\title{
O amor como caminho: ao encontro da educação e do património cultural
}

Luisa Janeirinho ${ }^{1}$

Devemos descobrir o poder do amor; o poder redentor o amor. E quando fizermos isso, faremos deste Velho Mundo um Novo Mundo. Luther King $^{2}$

Quando eu te encarei frente a frente

e não vi o meu rosto

Chamei de mau gosto o que vi, de mau gosto, mau gosto

É que Narciso acha feio o que não é espelho (...) E foste um difícil começo Afasto o que não conheço (...) (Caetano Veloso, Sampa)

O amor como caminho pode parecer, à primeira vista, um título inapropriado para trabalhar uma temática sobre educação $e$ património cultural. Poder-se-ia supor mais compreensível falar de amor - o amor como caminho - para uma reflexão que tivesse como

\footnotetext{
${ }^{1}$ Membro da Comissão de Coordenação da Catedra UNESCO “Educação, Cidadania e Diversidade Cultural luisajaneirinho.museudomundo@gmail.com

${ }^{2}$ Frase recordada pelo reverendo Miguel Curry durante a homilia do casamento Real, no dia 18 de maio de 2018.
} 
objetivo a relação/sentimentos entre pessoas - e é, na verdade, esse o objetivo.

A aproximação é feita na perspetiva em que Ortega $Y$ Gasset costura afinidades com o conceito plural e dinâmico que Platão anuncia na obra "O Banquete": um amor que não é definido de forma única e estática, mas traduzido por sete degraus. Se no primeiro degrau se ama o outro pela sua forma bela, na sua particularidade, o conceito evolui, progride, e alcança o amor pela ética, o amor pelas práticas belas - a integridade, justiça, bondade...-, o amor pelas instituições (pelo seu equilíbrio, harmonia, bem comum), pela ciência e pelo conhecimento e culmina no amor universal e cósmico e ama a beleza, enquanto princípio eterno do Universo - esse amor que é congénere da transcendência (Bauman, 2003).

Trago este tema, porque quando nos detemos nas grandes dificuldades sociais da nossa época e refletimos sobre as crises em que vivemos, em todos os âmbitos da ação do ser Humano e em todos os lugares, entendemos que as nossas práticas estão profundamente ligadas com uma determinada forma tradicional de se compreender o mundo: uma perceção da realidade que, não raras vezes, é reducionista, simplista e inadequada, que menospreza processos sistémicos, psicológicos e ecológicos presentes nos relacionamentos entre pessoas, sociedades e natureza e se distancia de valores humanos e existenciais, formadores de uma ética planetária.

O paradigma newtoniano-cartesiano de ver o mundo promoveu a separação entre o sujeito/objeto/conhecimento e provocou a fragmentação do sujeito e do conhecimento. Esta lógica de separabilidade tem condicionado o comportamento Humano ocidental - e todas as suas instituições. É uma lógica de objetividade assente num paradigma racionalista e economicista incapaz de interpretar e dar resposta à multi-dimensionalidade da própria crise e das novas realidades emergentes" (Herrero, 2006).

A proposta de um movimento a favor de um modelo que pretende substituir os paradigmas até agora em vigor, da fragmentação e da 
dicotomia - entre o sujeito, o objeto e o conhecimento; entre a tradição e a ciência; da própria fragmentação da ciência nas várias disciplinas - remete para Edgar Morin e para o paradigma da complexidade, na sua perspetiva do uno, do transdisciplinar, que cria uma comunicação entre as ciências e, também, para António Damásio quando adverte que "as ciências por si só não podem iluminar a experiência humana sem a luz que provém das artes e das humanidades" (Damásio, 2017, pag. 17).

$\mathrm{Na}$ urgência de construir um novo paradigma que dê resposta aos desafios que hoje se apresentam, que rompa com uma lógica de resposta a grupos de poder e se construa numa lógica de sustentabilidade e desenvolvimento, encontrando soluções para a marginalidade e a pobreza, seja solidária com as gerações futuras, contemple os níveis pessoal e social, seja pacifista, cooperativo internacionalmente, conhecendo, captando, decifrando, adquirindo valores éticos, respeitando a diversidade cultural (Rojo, 2008) tornase imprescindível uma atitude de reflexividade/hermenêutica/holística.

Así, es preciso realizar importantes cambios a todos los niveles, que abarcan desde la organización académica, hasta la oferta curricular o la cultura corporativa, pasando por las asignaturas, los contenidos, los espacios de reflexión institucional, la formación de los docentes, los servicios de extensión, la investigación, la vertebración con el entorno y con la sociedad... la docencia, la investigación, la extensión y la gestión, con miras a configurar una nueva cultura institucional, orientada por los principios del Desarrollo Sostenible, que permita concienciar y responsabilizar a toda la comunidad universitaria con la necesidad de actuar de acuerdo tanto con unas prácticas ambientalmente coherentes, como con los principios de la solidaridad con los demás pueblos del mundo y con las generaciones futuras (Herrero, 2006). 
Conforme nos refere Esteban, a escola desta nova modernidade líquida necessita pautar-se por princípios ecológicos e sustentáveis e por práticas de constante reflexividade, num olhar auto observador de crítica e interpretação interna das práticas, tomando a crise como uma estratégia para a aprendizagem e construindo espaços alternativos de conhecimento, de informação, de aprendizagem, de amor e creando un movimiento educativo de resistencia y crítica de la cultura y de la moral post-moderna (Valleriani, 2006).

La escuela crea, codifica y transmite una determinada gramática, no siempre visible, que se erige en cultura institucional. Los códigos de esta gramática regulan muchos procesos internos de la práctica escolar, se configuran como tradición $e$ informan el habitus de los que la profesan. Estos, los profesores, la asumen como memoria corporativa. Los alumnos también la internalizan y luego la extrapolan a la acción (Escolano, 2007).

Recentemente, António Damásio (2017), na sua obra, "A estranha ordem das coisas", desafia-nos, também, a um outro olhar sobre a origem dos processos. $\mathrm{O}$ neurologista e neurocientista refere que a cada momento aos sentimentos (a resposta à dor, sofrimento, compaixão, bem-estar) "indicam à mente, sem que profiram uma palavra, o bom ou mau rumo dos processos da vida no interior do respetivo corpo", não sendo uma "fabricação independente do cérebro", mas resultam duma colaboração entre corpo e cérebro, são os motivadores da criação intelectual, são os motivos para reagirmos a um problema, e monitorizam o êxito da resposta ou a falta dele.

Assim, é urgente restituir o equilíbrio existente na nossa vida e na vida do planeta; complementar o cognitivo, o emocional, o afetivo e o intuitivo e associar as expressões com a criatividade e a perceção; associar os processos cognitivos e emocionais com as capacidades de aprendizagem; promover a aquisição de competências 
intelectuais e artísticas, incentivar a totalização do conhecimento na formação holística do indivíduo - que atravessa fronteiras étnicas, religiosas e culturais e restitui uma visão mais Humanista do Eu e dos Outros.

"É certo que a lógica terá desempenhado um papel fundamental ao lidar com os factos, mas alguns desses factos cruciais eram sentimentos" (Damásio, 2017, pag. 32).

Na senda do Ano Europeu do Património Cultural (2018, UNESCO) e da Década Internacional para a aproximação de culturas (20132022, UNESCO) emerge uma oportunidade educativa que lança um olhar renovado para as potencialidades do património cultural.

O reconhecimento que o sucesso do processo educativo se concretiza numa base de contexto cultural de suporte, está mais além do que a simples promoção de programas/projetos de terreno que colocam em destaque a articulação entre a educação e a cultura (Educação Patrimonial) enquanto estratégia ativa de contextualização curricular.

O cerne está numa ação educativa, de âmbito "maior", capaz de dar resposta, não só ao sucesso curricular, mas a uma verdadeira Educação para uma Cultura de Paz - a única que poderá garantir um compromisso entre o aprender a SER e aprender a viver juntos dois dos quatro pilares da Educação expressos no Relatório para a UNESCO da Comissão Internacional sobre Educação para o Século XXI, coordenada por Jacques Delors (Educação: Um Tesouro a Descobrir, 1999) ${ }^{3}$.

A atualidade e a oportunidade deste documento advêm, sem dúvida, da tomada de consciência desta sociedade líquida e híbrida em que todos têm os mesmos direitos de fazer ouvir a nossa voz. A globalização, as diásporas, as viagens e os trânsitos trazem para o tempo atual um mundo de encontros, ou como refere Levi-Strauss, um mundo de mútua compenetração, uma civilização à escala

3 http://dhnet.org.br/dados/relatorios/a $\mathrm{pdf} / \mathrm{r}$ unesco educ tesouro descobrir.pdf 
mundial que é plural, mas também, intercultural e que nos coloca em confronto com o outro, que nos reflete em cada quotidiano o familiar e o diferente (Gramigna, 2008).

Esta sociedade complexa e feita de errância, de nomadismo e, como refere Valleriani, híbrida é feita por encontros culturais que desafiam os horizontes interpretativos pré-estabelecidos, ampliando o conhecimento pela exploração de outros signos radicalmente diferentes. O trabalho não se pode dissociar de uma sensibilidade que ajuda a cultivar o sentimento unitário de um estudo sobre a Humanidade, o elemento conetivo que entrelaça, em trajetos de significação, as diversas culturas. Partilho com Anita Gramigna (2008) que se trata de uma tensão estética e também ética que configura uma categoria hermenêutica de máximo interesse para um estudo e um tempo de complexidade, de intercultura. Nele, a trama da existência do encontro consubstanciase num profundo respeito a todas as culturas e formas de saber, sejam eles familiares e/ ou próximas ou desconhecidas e distantes e que, como nos refere Levi-Strauss, amplia horizontes interpretativos sobre a humanidade produzindo não só uma satisfação intelectual, mas também a leitura da "sagrada unidade do Todo".

As linhas orientadoras apresentadas no site do Ministério da Educação, para a Educação para a Cidadania, consideram que o "processo educativo visa contribuir para a formação de pessoas responsáveis, autónomas, solidárias, que conhecem e exercem os seus direitos e deveres em diálogo e no respeito pelos outros, com espírito democrático, pluralista, crítico e criativo" ${ }^{4}$.

Também, o mesmo documento refere as diferentes dimensões da educação para a cidadania, que se expressa numa abordagem transversal em função das necessidades e problemas específicos da comunidade educativa, nomeadamente a Educação para o Desenvolvimento, para os Direitos Humanos e a "A Educação Intercultural, que pretende promover o reconhecimento e a

\footnotetext{
${ }^{4}$ http://www.dge.mec.pt/estrategia-nacional-de-educacao-para-cidadania
} 
valorização da diversidade como uma oportunidade e fonte de aprendizagem para todos, no respeito pela multiculturalidade das sociedades atuais (...) criadora de identidades e de sentido de pertença comum à humanidade".

Tomando como pano de fundo os documentos orientadores a nível internacional e nacional é de salientar que se toma o processo de educação de forma ampla, em que os objetivos estão para além dos resultados escolares que se projetam alcançar, mas integrando-os, tendo subjacente que a Educação se apresenta como o garante de sucesso, a longo prazo, para as novas conceções e compreensão do Mundo e na aprendizagem a viver juntos.

É importante ter em conta que a instituição escolar, embora sendo um modelo mundializado, encerra alguns constrangimentos de diálogo com as culturas em presença: o ethos da cultura tem, não raras vezes, como suporte a tradição oral e o saber fazer construído de forma empírica, intuitiva e indiciária que mobiliza saberes multidisciplinares para a sua existência e continuidade e, por isso, nem sempre encontra eco na instituição escolar, pois "esbarra" em modelos racionais de aprendizagem e de fragmentação do conhecimento.

Destas circunstâncias, a oportunidade da recente Cátedra da Universidade Lusófona, aprovada pela UNESCO, em cuja apresentação se pode ler:

"A Cátedra "Educação, Cidadania e Diversidade Cultural" é um programa de formação e extensão universitária que trabalha conteúdos educativos e culturais como um contributo de valor incontornável para a afirmação de políticas de desenvolvimento. Apresenta e promove a programas de formação e procura soluções para a construção dum mundo com base em economias de bemestar, em sociedade justas e inclusivas, com respeito pela sustentabilidade ambiental. Trabalha sobre as questões da igualdade de género, do trabalho digno; das cidades sustentáveis inclusivas e da governação transparente e das parecerias no âmbito duma educação para a paz e para a cidadania global e promove 
possibilidade de criação de emprego no âmbito da economia criativa" ${ }^{5}$.

Assim, o projeto que esta Cátedra inclui, pode-se constituir como um trabalho que dá resposta aos objetivos que hoje se impõem à sociedade (e às suas instituições) na medida em que se apresenta como a construção de um espaço de partilha e aprendizagem das culturas em presença, de conhecimento e respeito pela diversidade cultural e de construção de situações de efetiva cidadania.

O impacto positivo que advém dos projetos de Educação Patrimonial, para as escolas e para as comunidades inscreve-se nos desafios que hoje se apresentam à sociedade civil e às instituições e revelam a necessidade de sermos agentes ativos nas respostas sociais de um Mundo globalizado, interdisciplinar e intercultural, com vista ao sucesso e ao verdadeiro exercício de cidadania- eixos de ação preconizados, nomeadamente, no Despacho n. 6173/2016, de 10 de maio de 2016 (Cidadania, Direitos Humanos e Igualdade de Género), no Despacho n. 9311/2016, de 21 de julho (Perfil dos alunos à saída da Escolaridade Obrigatória) e no Despacho n.으 $5908 / 2017$, de 5 de julho, no que respeita à autonomia e flexibilidade curricular ${ }^{6}$.

\section{Educação Patrimonial, porquê?}

Em resumo, tendo como base as várias experiências no terreno e a investigação produzida, podem-se apontar como eixos da educação patrimonial:

1- O estudo da diversidade do património cultural põe em evidência a diversidade da ação Humana, preservando e valorizando.

2- A construção de um conhecimento partilhado pressupõe modelos interpretativos participados pela diversidade de visões e mobiliza, não só, conhecimentos, mas atitudes e valores, num processo de construção da cidadania.

\footnotetext{
${ }^{5}$ https://www.ulusofona.pt/news/educacao-cidadania-unesco

6 Desta circunstância o projeto piloto de Educação Patrimonial apresentado ao Ministério da Educação e Ciência, em 2018.
} 
3- A compreensão da diversidade do património cultural requer propostas de ensino-aprendizagem ativas, significativas, afetivas e lúdicas, a partir de situações concretas e modelos inovadores de contextualização curricular.

4- Os projetos educativos empreendidos na ligação entre escola $X$ comunidade respondem aos desafios do respeito pela diferença, na gestão e diferenciação pedagógica.

5- O património cultural, sendo uma realidade multidisciplinar, promove trabalhos interdisciplinares.

6- A flexibilidade curricular é o garante de propostas e processos plurais de acesso ao conhecimento e de contextos diversificados de aprendizagem - formais, informais e não formais.

\section{EDUCAÇÃO PATRIMONIAL}

O que é?

É o espaço de relação construído e partilhado entre o processo educativo (das pessoas/comunidades) e o património cultural;

Tem como centralidade o espaço de partilha relacional educação X património cultural.

Interpreta, produz conhecimento sobre o património (material, imaterial) e identifica o significando cultural:

Lugares: a praça, o mercado, a rua, a habitação e os objetos associados

Tempos: festividades, comemorações, rituais

Expressões: linguagem (estórias, lengalengas, vocábulos) arte: música, pintura, design saber-fazer: gastronomia, ofícios tradicionais....

Ambiente: relacionando-o com o processo cultural

\section{Objetivos}

Pesquisar, recolher e organizar informação sobre referências/bens culturais que estão presentes nas histórias dos grupos culturais, que são coletivamente partilhadas, representam e identificam uma comunidade. 
- construir conhecimento a partir do diálogo entre a educação e o património (escola $X$ comunidades $X$ bens culturais);

- promover a compreensão e o respeito pelas diferenças dos bens culturais e das comunidades que lhes estão na origem;

- articular ativamente o conhecimento das comunidades em presença (educativa e outras);

culturas

- construir "novos conhecimentos" pelo encontro de

\section{Como se concretiza?}

Trabalho de campo

Trabalho de pesquisa no terreno - entrevistas, recolhas orais a pessoas das comunidades envolvidas

-registos escritos, desenhos, fotografias

- diários de campo

- guiões/roteiros de visitas e de observação

Recolha, organização e divulgação da informação - trabalho de projeto

- utilização de suportes variados

- utilização da TIC

Formação/sensibilização -

em etnoeducação (para professores, técnicos e interlocutores) metodologias ativas de contextualização curricular

A etnoeducação, enquanto metodologia das Ciências Humanas e Sociais, visa o cruzamento entre a educação e os estudos etnográficos/culturais, materializa-se no trabalho de campo e na "intencionalidade educativa" na produção do conhecimento, pela interpretação e respeito da multiplicidade de visões.

A causa de nós não termos ido para a delinquência 
e para o mundo da droga, o que era comum em pessoas que vinham de bairros como nós, era essa: o AMOR (Matias Damásio, entrevista, 2018)

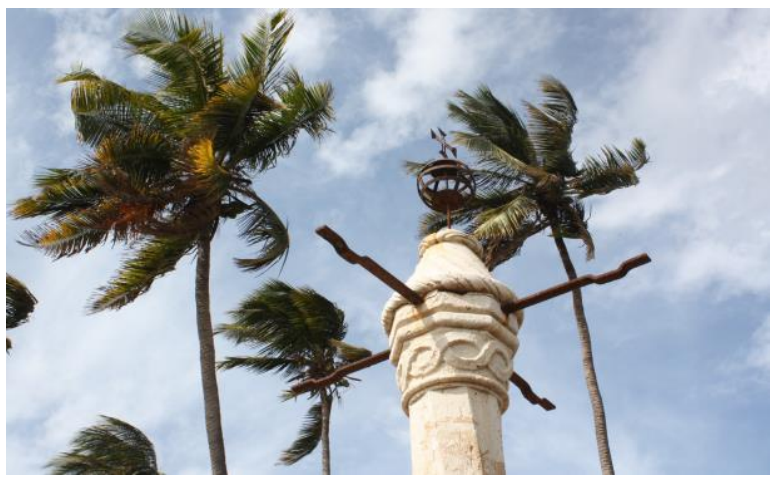

Fotografia: António Adão

\section{Inspira-te, património criativo}

O princípio (não) foi o verbo!

A estrada que liga a Cidade da Praia (capital de Cabo Verde) à Cidade Velha, hoje asfaltada, mas em 2010 de difícil acesso; os 10 km de caminho, de paisagem perturbante e "perturbada" pela "bruma seca" que se faz sentir no mês de janeiro; a curva cimeira com o Forte de S. Filipe do lado direito e o mar à esquerda, faz daquele casario ao fundo, recortado no mar - para onde a estrada que desce nos leva e que o olhar teima em ver - um lugar mágico!

Ficar, não é seguir o trilho da razão, mas do sentir.

As razões que levaram a Comissão da UNESCO a eleger a Cidade Velha como Património da Humanidade, em 1999, está para além do que podemos ler sobre o assunto. A Praça do Pelourinho, a Rua Banana, a Igreja de Nossa Senhora do Rosário ... cruzam-se com os cheiros, sons e sabores do caldo de peixe, da sucrinha, das batucadeiras, das mangueiras, do mar... e com as pessoas e a sua

Pessoas e culturas
em viagem
que chegaram, se
cruzaram e
voltaram a partir
levando um
pouco to
de tudo e todos,
mas deixando
um "pequeno
laboratório", de
tão que
grande valor, que
Charles Darwin,
ao visitá-lo,
"descobriu" a
Teoria da das
Origem a

Pessoas e culturas se tir $\mathrm{m}$ 
morabeza...e com a memória do lugar - porque a Cidade Velha é um lugar de memória.

A ação Humana é construída numa trama de sonhos, desejos, razão, vitórias e perdas, encontros e desencontros, momentos de glória e de desistência. $O$ projeto aqui apresentado embora não fugindo a esta regra, tornou-se especial para os que nele participaram, porque a Cidade Velha é um lugar especial.

A Cidade Velha é uma das "Cidades Mundo", assente na transculturalidade, numa ética de alteridade, habitada pelo universalismo da diferença, das culturas em viagem e das identidades em construção. Lembro aqui o conceito de António Valleriani, uma Cidade Mundo ${ }^{7}$, uma cidade de encontro de pessoas de vários lugares, proveniências culturais distintas, credos, medos e sonhos, que construíram num território o espírito de um lugar híbrido - a que chamamos o berço da nação crioula. Daí não ter sido por mero acaso que a Câmara Municipal da Ribeira Grande de Santiago tivesse acolhido, para nascer naquele município, a Rede das Cidades Mundo, em 2012, e que o tema das Cidades Mundo se tivesse inscrito na Cátedra da UNESCO, já referida, conforme consta da sua apresentação.

"A cátedra promove a ligação de pessoas, constrói pontes e valoriza uma relação consciente entre a educação, a economia e a diversidade das expressões culturais. Parte do reconhecimento $e$ valorização da diferença para criar e desenvolver competências de inovação social no contexto de cidades-mundo. Cidades que são protagonistas de práticas da Diversidade Cultural a partir das heranças lusófonas do mundo mediterrânico, atlântico e indico".

${ }^{7}$ O conceito de Cidade-Mundo foi cunhado por António Valleriani, filósofo italiano, para o projeto Museu do Mundo e tinha como base o ethos do híbrido e da cultura barroca, presente em Portugal. 
O trabalho empreendido na Cidade Velha, de 2011 a 2017, pela concretização do Projeto Museu do $\mathrm{Mundo}^{8}$ sediado na associação SPHAERA MUNDI, com o tema: Inspira-te, património criativo: educação patrimonial, empreendedorismo cultural e turismo de conhecimento, embora com vários eixos e ações no terreno, teve sempre como objetivo principal Educar para uma Cultura de Paz, sabendo que a educação patrimonial é a ferramenta capaz de gerar processos educativos e criativos nas comunidades, envolvendo os seus diversos agentes, interligando conhecimentos, pondo em diálogo gerações e os seus saberes.

O trabalho desenvolvido no terreno teve por base este novo paradigma que visa realçar e ampliar o poder educador do património, servindo objetivos de integração e de desenvolvimento das populações (bem patentes nos Princípios de Base de uma Nova Museologia - Declaração de Quebéc, 1984).

Mário Moutinho (2012) lembra que este tipo de trabalho visa consolidar o reconhecimento do património (e da museologia) como recurso para o desenvolvimento sustentável da humanidade, assente na igualdade de oportunidades, na inclusão social e económica e na intervenção social no património cultural e natural, tangível e intangível da humanidade. Refere ainda, a necessidade de abordagens interdisciplinares, em que se privilegia a articulação da museologia, em particular, com as áreas do conhecimento das Ciências Humanas, dos Estudo do Desenvolvimento, da Ciência de Serviços e do Planeamento do Território, constituindo-se uma área disciplinar de ensino, investigação e atuação: a Sociomuseologia (Moutinho, 2012).

O projeto desenvolvido na Cidade Velha, Património da Humanidade, sustentou-se em torno de dois eixos - Educação patrimonial e Empreendedorismo cultural (ligados a um turismo de conhecimento) - todos eles resultantes da necessidade da

${ }^{8}$ O projeto Museu do Mundo ganhou, em 2004, o 2o lugar no concurso de ideias de negócios, dos Business Angels, Cascais e a CPLP atribuiu-lhe o seu Alto Patrocínio. 
valorização e dinamização do estatuto atribuído à Cidade Velha, como Património Mundial e da urgência do estatuto atribuído ser gerador de rendimento sustentável para as comunidades - tendo em conta, por um lado, a necessidade que os mais jovens se apropriem e valorizem o seu património local e, por outro lado, que as comunidades retirem benefícios diretos para o sustento das famílias, tendo em conta a elevada taxa de desemprego e pobreza da população do Município da RGS.

1ํ. Eixo - Educação patrimonial

1- Fomentar uma educação para uma cultura de paz, com base na educação/património;

2- Promover e dinamizar o património como valor identitário cultural e de desenvolvimento sustentável;

1- Conhecer e valorizar o património material, imaterial e natural da Cidade Velha:

2- Promover a escrita, a pesquisa, o conhecimento direto sobre o património, de forma lúdica e criativa;

3- Promover a pesquisa e o trabalho de projeto, nas escolas.
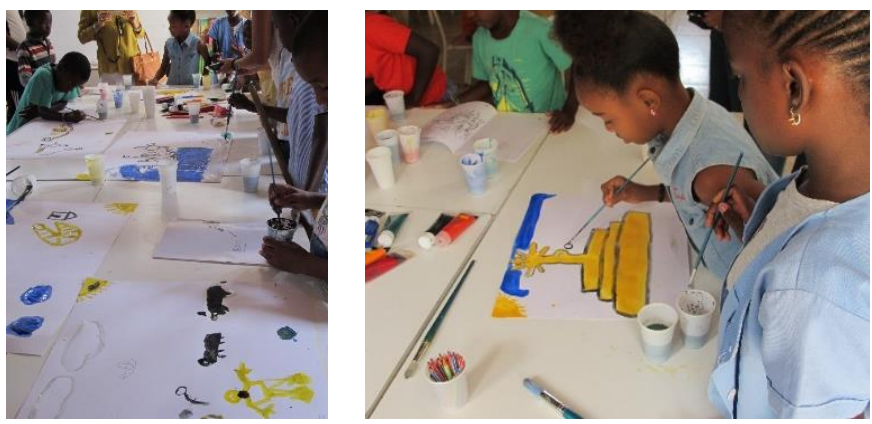


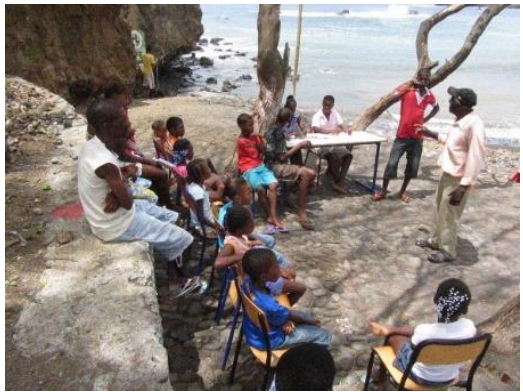

Fotografias:SPHAERA MUNDI

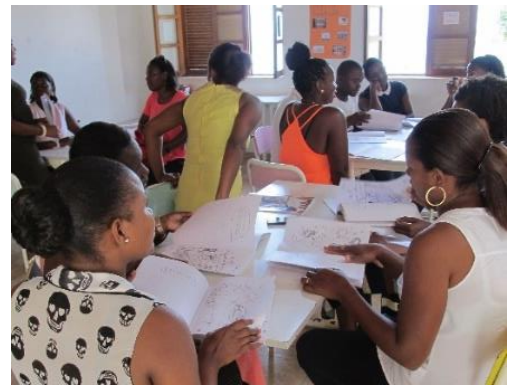

O projeto iniciou-se por um conjunto de ações de sensibilização com as escolas/alunos, professores, técnicos, artesãos e comunidade em geral, sobre o património material, imaterial e natural, existente na Cidade Velha, através de visitas, debates, sessões de estórias, pinturas - trabalho em parceria com a Câmara Municipal da Ribeira Grande de Santiago, com a Comissão Nacional de Cabo Verde para a UNESCO (CNU) e com o Ministério da Educação, para além de outras colaborações locais.

Com o objetivo de consolidar o trabalho realizado, mas, também, estender a valorização deste Património da Humanidade para além das fronteiras da Cidade Velha, em colaboração com a CNU, procedeu-se à organização de um conjunto de cadernos criativos para escrever e pintar, com o título: Inspira-te, património criativo.

Os desenhos para colorir, com as suas perguntas de partida, inspiram à pesquisa, ao encontro com a comunidade local, na procura de respostas que permitam a organização de textos escritos pelos alunos, sobre cada desenho apresentado, possibilitando que cada aluno construa a sua versão da História e das estórias, tendo subjacente as recolhas produzidas - para que os cadernos se constituam como desafios que a leitura, a escrita, a arte e o património promove.

Os desenhos produzidos por um jovem artista local, apresentam temas ligados ao património, que vão desde a descoberta da História e das estórias do Pelourinho, da cimboa, do imbondeiro, do Vale Verde e da tabanka, entre outros, tendo como inspiração o 
património local e os desenhos produzidos pelos alunos.
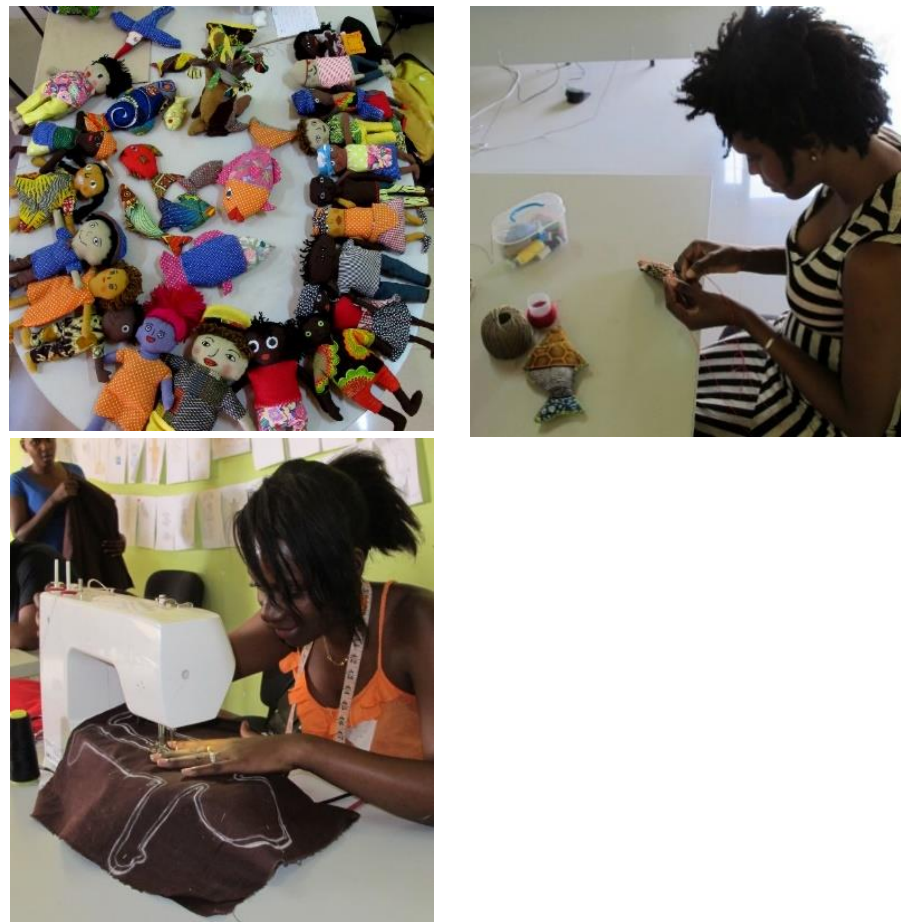

Fotografias: Born Africa

Dando resposta ao 20 eixo do projeto - empreendedorismo cultural e turismo de conhecimento, os desenhos para colorir serviram de repto para a construção de novos desenhos feitos pelos alunos, sobre os temas. Estes desenhos constituíram a base para a organização de moldes e para a confeção de personagens do património cultural da Cidade Velha e foram produzidos pelas mães dos alunos ou outras artesãs/ãos da comunidade local.

Este segundo eixo do trabalho, que contou com o apoio da Cooperação Portuguesa/Instituto Camões, teve a mais valia de integrar a parceria com a associação local Born:África e o seu projeto Storia, Storia, cujo objetivo se adaptou ao projeto em curso. Toda dinâmica gerada, para além de fomentar a ligação escola- 
família e um trabalho articulado entre os alunos e os pais, constituiu-se, com a venda dos personagens, uma fonte de rendimento para as mães/famílias, o que permitiu a experiência do património se constituir como um fator de rendimento direto, fomentando uma cultura criativa com base no saber fazer tradicional/local.

\section{Em jeito final}

Cidades Mundo - Quem sou eu?

Ao reconstruir as motivações que estiveram presentes no trabalho realizado, ao rememorar o ponto de partida e a trajetória de todos os envolvidos no projeto, surge como móbil, de forma mais ou menos consciente, a pergunta: quem sou eu?

Este projeto mostra o valor criativo da memória, que promove a ação e é empreendedora rumo ao desenvolvimento. A memória de uma Cidade Mundo, quando revelada em todos os seus detalhes, não é pretérita e fixa, mas uma capacidade de narrativa que nos impele à ação e em que todos nos revelamos e relemos. Uma memória partilhada coletivamente, com registos oficiais mas, também, outros que se encontram silenciados, traduzida em detalhes íntimos e subjetivos, que integram a biografia pessoal de cada sujeito - o seu património pessoal.

A potencialidade educadora do património torna-se ação em cada desenho, estória e personagem produzido - é Janus, o Deus das portas e dos portais, do passado e do futuro, em que as duas faces em oposição são necessárias pois simbolizam a ponte onde reside o eterno presente, que se torna promessa de futuro. Os bonecos de pano produzidos pelas artesãs/ãos, não são mais bonecos, mas personagens do mundo real daquela comunidade, íntimo e estético, num desafio do saber fazer tradicional e do enlace entre o coletivo e o particular - a sua estória. É na perspetiva apresentada por Umberto Eco que o objeto (os personagens) aqui se apresentam: um objeto visto para além da sua materialidade, da sua inércia, transformado num guia evocativo da memória, um "lugar" que se desdobra em vários tempos e histórias que permitem edificar 
percursos pessoais narrativos e revelar um lado esquecido do património - aquele que é construído pelos detalhes e sentidos do quotidiano, a cultura empírica.

Neste projeto procurou-se revelar a força educadora do património acionando os conteúdos da memória ligada à construção da história oficial e, também, à escrita das memórias individuais. A primeira constrói um continuum de acontecimentos, registando e preservando o que a memória tem de coletivo, a valorização de factos, dados e pessoas, cuja importância atribuída concorreu para a sua preservação. A segunda enfoca as descontinuidades e ruturas, realça as diferenças, faz emergir temas marginais. Esta memória torna-se ativa, desenraíza os acontecimentos passados da linearidade da história coletiva, apresentada pela história tradicional e marcada por estratégias de poder (Foulcault, 1979).

É, como nos lembra Mário Chagas, uma sociomuseologia comprometida com a sociedade que, mais do que um espaço é um território, mais do que utentes tem redes e mais do que temas tem problemas. Afastámo-nos da tendência para a celebração da memória do poder (instituições etnocêntricas e de totalidade das coisas e seres), assumindo a heterogeneidade e incoerência, onde circulam memórias e contra memórias e onde o património coletivo e memória são colocadas ao serviço da sociedade, do seu desenvolvimento e intervenção (Chagas, 2009).

Neste projeto de valorização da educação e do património foi convocada, não só, a memória oficial, mas, também, a contida em relatos de indivíduos que consagram descontinuidades e interrupções. A emergência destas memórias marginais - descritas na batucadeira Nhã Pomba, no pescador, na peixeira...- remetem para o conceito de "contra-memória" de Foulcault (1986), pois permitem a revisão do "regime de verdade" da memória, e subtraem as versões cristalizadas do passado, propondo novos regimes da abordagem da história e da memória, numa linha da decolonização do património e da museologia, como nos fala Marcelle Pereira (2018). 
A finalizar, retomemos o ponto inicial do desafio deste projeto Inspira-te, património criativo - sendo que esta criatividade que se apresentou de forma externa - em desenhos, pinturas e personagens, em relações com pessoas e entre pessoas, com os espaços, os tempos e as memórias... - foi trilhado numa procura de sentimentos positivos para a biografia pessoal e de valorização da estória da comunidade (o amor como caminho) - pois a interioridade dos objetos desdobra-se em múltiplas histórias, tempos e espaços que remetem para o Aleph, de Jorge Luís Borges (1998) - romanceado pela mão de Paulo Coelho - um espaço cósmico, em nada diminuído, em que cada coisa são infinitas coisas, porque se veem, claramente, todos os pontos do Universo:

Estou no Aleph, o ponto onde tudo está no mesmo lugar ao mesmo tempo.

Estou numa janela a olhar para o mundo e para os lugares secretos, a poesia perdida no tempo $e$ as palavras esquecidas no espaço.

Estou diante de portas que abrem por uma fração de segundo e logo se tornam a fechar, mas que permitem desvelar o que está escondido por detrás delas. (...) Não estou no passado, estou no presente. Eu sou agora aquele menino que fui. Serei sempre aquele menino, todos nós seremos as crianças, os adultos, os velhos que fomos e que tornaremos a ser. Eu não estou a LEMBRAR. Estou a viver de novo esse tempo (Coelho, 2010).

\section{Bibliografia}

São sempre vários os livros, artigos e sites consultados. Se de alguns aqui não deixo a referência, foi um lapso de memória. Mas agradeço a ideia deixada e a possibilidade de futura correção. Livros

Bauman, Zygmunt (2001), Modernidade Líquida, Zahar, Rio de Janeiro;

Bauman, Zygmunt (2006), Amor Líquido, Relógio d’Agua, Portugal; 
Borges, J. (1999). O Aleph (3.a reimpressão.). São Paulo: Editora Globo;

Chagas, Mário (2009), Memória e poder: dois movimentos, Cadernos de Sociomuseologia, [S.I.], v. 19, n. 19, june 2009. ISSN 1646-3714. Disponível em: <http://revistas.ulusofona.pt/index.php/ cadernosociomuseologia/article/view/367;

Coelho, P. (2010). O Aleph. Rio de Janeiro: Editora Pergaminho;

Eco, U. (2005). A misteriosa chama da rainha Loana. Algés: DIFELDifusão Editorial;

Escolano Benito, Agustin ; Diaz Jose Maria, coords (2002) "La memoria y el desejo - la cultura de la escuela y educacion deseada", Ceince;

Escolano Benito, Agustín; La Cultura empírica de la Escuela, Aproximacion Etnohistórica y Hermenéutica, Universidad de Valladolid, Ceince;

Esteban Ortega, J. (2009). La educación líquida desde la institucionalización sociocultural del arte actual: una perspectiva hermenéutica. Estudios filosóficos, vol. 58, n. 167;

Fentress, James (1992), Memória social, novas perspectivas sobre o passado, Coleção Teorema, Lisboa;

Foucault, M. (1979). Genealogia e poder. In R. Machado (Org.), Microfísica do poder. Rio de Janeiro: Edições Graal;

Godek, Gregory (1997) Love, The course they fargot to teach you in the school, Casablanca Press, USA;

Gramigna, A. (2008). Estética etnografica y pedagogia interpretativa: por una poética de la comprensióm del mundo. In J. Esteban Ortega (Ed.), Cultura, hermenéutica y educación (pp. 1122). Valladolid: Servicio de Publicaciones de la Universidad Europea Miguel de Cervantes-CEINCE;

Janeirinho, Luisa (2015), Educação e Património, estudo da cultura material da escola numa perspetiva hermenêutica, etnohistórica e pós colonial; tese de Doutoramento, Universidade de Sevilha; KENSKI, Vani (1997), Sobre o conceito de memória, in Ivani fazenda (org.) A pesquisa em educação e as transformações do conhecimento; Brasil Papirus; 
Magalhães, Dulce (2006), a Paz como caminho, Festival mundial da Paz, Brasil;

Morin, Edgar (1994), Ciência com Consciência, Plublic. Europa América, Lisboa;

Moutinho, M. (2012). Definição evolutiva de sócio museologia proposta de reflexão. Acedido a 20 de maio de 2013, www.minomportugal.org;

Ortega, Joaquin Estebaned. (2008) Cultura Hermenèutica y Educación Univer. Miguel Cervantes, CEINCE;

Pereira, Marcelle (2018), Museologia Decolonial, os ontos de memória e a insurgência do fazer museal, Tese de Doutoramento, Universidade Lusófona de Humanidades e Tecnologias, Lisboa;

Valleriani, A. (2006). Pellegrini nel labirinto del mondo e del vivere : Gracián e Comenio educatori del barocco. Milano: UNICOPLI;

Valleriani, A. (2009 a). Memoria e patrimonio in educazione. [S.I.: s.n.];

\section{Textos}

Estratégia Nacional de Educação para a Cidadania, setembro de 2017,

Herrero, Henar (2006), "La educación Superior frente al espejo de la sustenibilidad" in, "Escolano Benito, A, "Educación Superior e Desarrollo Sostenible. Madrid, Biblioteca Nueva.2006;

Ortega, Joaquin (s/d), "Sociedad líquida, reflexividady educación" documento em suporte digital.

Rojo, Martim (2008), "Ecocurriculum, Fundamentos de la didáctica crítica", documento copiado;

Valleriani, António; (s/d), Emancipación y tragedia en pedagogíaLuis Eduardo Primero Rivas y la Pedagogia de lo Cotidiano, documento em suporte digital.

\section{Sites}

file://C:/Users/luisa.janeirinho/Desktop/2018\%20Educação\%20Pat rimonial/ARTIGO\%20\%20EDUCACAO\%20PATRIMONIAL\%20NAS\%20 
ESCOLAS\%20UMA\%20ALTERNATIVA\%20PARA\%20A\%20PRESERVAC AO.PDF

file://C:/Users/luisa.janeirinho/Desktop/2018\%20Educação\%20Pat rimonial/Educação\%20patrimonial\%20lido.pdf

file://C:/Users/luisa.janeirinho/Desktop/2018\%20Educação\%20Pat rimonial/UNESCo\%20Programa\%20em\%20Educação\%20Patrimonial .pdf

file://C:/Users/luisa.janeirinho/Desktop/2018\%20Educação\%20Pat rimonial/cadernos-de-cultura-vol-2.pdf 